\title{
NEURODEGENERATION
}

\section{A traffic jam leads to Lewy Bodies}

Tim Bartels.

Affiliation: Dementia Research Institute, University College London, London, United Kingdom. Ann Romney Center for Neurologic Diseases, Brigham and Women's Hospital and Harvard Medical School, Boston, USA. Email: t.bartels@ucl.ac.uk

\section{Shamahmoradian and colleagues report that the structure of Lewy Bodies in Parkinson's Disease consists of alpha-synuclein and lipid vesicle clusters instead of the long assumed amyloid fibril core. This finding has implications for our understanding of the underlying pathogenesis of synucleinopathies.}

What goes awry when we develop brain diseases? Research into the pathogenesis of neurodegenerative disorders typically focuses on protein misfolding and aggregation. The pathological hallmark of these disorders is focal accumulation of a specific protein -- Amyloid- $\beta$ in Alzheimer's or alpha-synuclein ( $\alpha$-Syn) aggregation in Parkinson's Disease (PD) - which have a propensity to aggregate and deposit in the brain.. For most neurodegenerative diseases these protein inclusions are thought to consist of amyloid fibrils, rod-like protein structures with a predominantly $\beta$-sheet fold. Assembly of these proteins into amyloid fibrils is thought of as the toxic event driving cell death. For PD, structural analyses of its pathological hallmarks, the socalled Lewy Body in the soma of a cell and the Lewy Neurite along its processes, have revealed a dense accumulation of $\alpha$-Syn (1) consisting of amyloid fibrils (2). These findings have driven therapeutic and diagnostic research over the last two decades towards studying the $\alpha$-Syn amyloid formation.

In their structural analysis of Lewy Bodies, Shamahmoradian et al. (3) now take a fresh look at patient brain tissue and find an unexpected answer to the question of what makes up a Lewy Body. Using correlative light and electron microscopy (CLEM) they show that the vast majority of Lewy Bodies actually consist of clusters of various membranous compartments instead of the previously assumed wide-spread amyloid. The indication of vesicle trafficking defects and the absence of fibril formation in the pathology of PD has several important implications for future research of disease mechanisms.

Traditional structural analysis of Lewy Bodies relied on light microscopy of a-Syn accumulation via immunohistochemical staining (4). These techniques lack the resolution to provide structural 
information on the basis of focal accumulation. By contrast, ultrastructural techniques like electron microscopy (EM) are mainly guided by visual inspection of anticipated structures. Given the absence of protein specific markers that would indicate all points of interest, only spots that showed characteristic rod-like structures were analyzed in the past, assuming that both microscopy and EM were looking at all present $\alpha$-Syn inclusions. The important new findings of Shamahmoradian et al. (3) stem from a barrage of cutting-edge imaging techniques the authors have employed to look in detail at the Lewy Bodies and Lewy Neurites in the brains of PD patients.

The authors identified $\alpha$-Syn aggregates by immunohistological staining and, using the CLEM technique, directly conduct EM ultrastructural analysis of the same inclusion. This allowed them to now probe what an average classically defined Lewy Body or Neurite looks like at the EM level. Via this approach, and extending it using serial block-face scanning electron microscopy, the authors identified various vesicle clusters coated with high local concentrations of nonfibrillar $\alpha$-Syn molecules in the core of a Lewy Body, explaining the punctate appearance of $\alpha$ Syn staining in past neuropathological analysis. Unexpectedly, only about $20 \%$ of all Lewy Bodies and Neurites appeared to have large amyloid fibrils associated with them, indicating that $\alpha$-Syn aggregation is not as integral to PD pathology as formerly believed.

Interestingly, morphological analysis led to the identification of various lysosomal vesicles associated with the core, and further mitochondrial membranes at the periphery of the Lewy Bodies. To confirm these initial findings, the authors followed up with a larger cohort of PD patients and used super-resolution microscopy combined with immunohistological staining for several lipid membrane markers. Analysis here corroborated the presence of mitochondrial markers, as well as vesicles involved in different stages of lysosomal degradation. Finally, using Raman scattering and infrared spectroscopy, the authors were able to demonstrate that the core of Lewy Bodies was indeed made up of large amounts of lipids, which mass spectroscopy of laser-captured Lewy Bodies found them to be rich in sphingomyelin and phosphatidylcholine.

Though the study lacks direct mechanistic insight, the presence of lipid vesicle clusters and the relatively common absence of amyloid deposits in these pathological hallmarks of PD has implications for future research. First of all, it puts previous research on amyloid formation in PD in question. The field has been dominated by intense research into smaller aggregates of $\alpha$ Syn that are thought to be the main toxic agent in PD. Recently this research has shifted into larger amyloid species that potentially display prion-like behavior, in part explaining some of the progression of pathology. All of these approaches assumed $\alpha$-Syn amyloid aggregation to be central to its neurotoxicity. If, as indicated by the authors, Lewy Bodies are largely composed of mistrafficked lipid vesicles instead of fibrillar protein, this could lead to a paradigm shift that focusses on lipid interactions with $\alpha$-Syn as a potential target for understanding and therapeutically targeting neurodegeneration in PD.

In that respect, lipid metabolism, lipid interaction and traffic vesicle dysfunction have been demonstrated in the past to be of importance for PD. In vivo, $\alpha$-Syn is reversibly associated with membranes (5), an interaction mediated by the first 100 amino acids of its $\mathrm{N}$-terminal region (6), and all mutations of the $S N C A$ gene (which codes for $\alpha$-Syn and leads to familial PD) are located in this lipid binding domain. Several other risk genes like LRRK2/PARK8, RAB7/PARK16, VPS36/PARK17 and SYNJ1/PARK20 support a strong genetic link between proteins involved 
in vesicle-trafficking and PD pathogenesis. In addition, one of the most important and significant risk factors for PD besides SNCA and LRRK2 is GBA (7). Homozygous GBA mutations result in defects in sphingomyelin metabolism leading to Gaucher disease, a developmental disease characterized by lysosomal dysfunction.

Additionally, lipids and fatty acids are modulators of $\alpha$-Syn function. Recent lipidomic screens identified fatty acid metabolism enzymes can be targeted to modulate $\alpha$-Syn toxicity (8). Vesicle clustering seems to be one of $\alpha$-Syn's physiological functions (9). But if this function is exaggerated by either overexpression or mutations, this vesicle clustering can be neurotoxic $(10,11)$. While several of these model systems demonstrated a strong link between $\alpha$ Syn vesicle clustering and neurotoxicity, amyloid aggregation did not seem to be a part of their phenotypic presentation and therefore their link to clinical pathology was previously unclear. The study by Shamahmoradian et al. now potentially reconciles these findings with the pathology of PD brains, suggesting both $\alpha$-Syn-lipid interaction and amyloid aggregation deserve a place in the spotlight of PD research.

These two mechanisms are not mutually exclusive and should be studied as two sides of the same coin. In fact, amyloid formation can be catalyzed by vesicle binding (12), and membrane interactions are important for the formation of aggregation-resistant forms of $\alpha$-Syn $(13,14)$. And while a recently published PD mouse model with a strong neurodegenerative and movement disorder phenotype had $\alpha$-Syn-positive inclusions rich in vesicle clusters in young mice, older animals seemed to have more classical amyloid aggregates (15). This could indicate that aberrant vesicle clustering is potentially early in the formation of a Lewy Body, while amyloid fibrils are the hallmark of a later, more mature inclusion. If later studies analyzing larger PD cohorts indeed validate that only roughly $20 \%$ of human disease Lewy Bodies contain amyloid fibrils, this might actually indicate a distribution of early vs. late stage $\alpha$-Syn-positive inclusions within the same individual, with lipid binding having a central role in fibril formation (see Figure 1).

Understanding how $\alpha$ Syn interacts with physiological membranes to induce disease, or finding a therapeutic pathway to target this, will require further research. But the fascinating observations made here by Shamahmoradian et al. in disease tissue will allow us to greatly improve our model systems going forward, bringing us a step closer to understanding the disease.

Figure 1: Different models of $\alpha$ Syn dysfunction in disease. Upper panel: In the traditional model, cytosolic $\alpha$ Syn aggregates directly into large fibrillar structures that make up the classical pathological hallmark of synucleinopathies, the Lewy Body. Lower panel: The novel data by Shahmamoridan et al. now implicates a new model. In the disease state, physiological interaction of membrane bound $\alpha$-Syn with trafficking vesicles goes awry, leading to excessive clustering of vesicles by $\alpha$-Syn. If these lipid-protein aggregates are not dissociated they further become insoluble and are then detected as the classical Lewy body. Alternatively, or consecutively, high local concentrations of $\alpha$ Syn bound to vesicle clusters lead to amyloid fibril formation in late stage Lewy Bodies (picture courtesy of Mel Feany, Brigham \& Women's hospital). 
References:

1. Spillantini MG, Schmidt ML, Lee VM, Trojanowski JQ, Jakes R, Goedert M. Alphasynuclein in Lewy bodies. Nature. 1997 Aug 28;388(6645):839-40.

2. Spillantini MG, Crowther RA, Jakes R, Hasegawa M, Goedert M. alpha-Synuclein in filamentous inclusions of Lewy bodies from Parkinson's disease and dementia with lewy bodies. Proceedings of the National Academy of Sciences of the United States of America. National Academy of Sciences; 1998 May 26;95(11):6469-73. PMCID: PMC27806

3. Shahmoradian SH, Genoud C, Graff-Meyer A, Hench J, Moors T, Schweighauser G, Wang J, Goldie KN, Suetterlin R, Castano-Diez D, Perez-Navarro P, Huisman E, Ipsen S, Ingrassia A, de Gier Y, Rozemuller AJM, Da Paepe A, Erny J, Staempfli A, Hoernschemeyer J, Grosserueschkamp F, Niedieker D, El-Mashtoly SF, Quadri M, van IJcken WFJ, Bonifati V, Gerwert K, Bohrmann B, Frank S, Britschgi M, Stahlberg H, van de Berg W, Lauer ME. Nat. Neurosci. https://dx.doi.org/xxx (2019).

4. Braak H, Del Tredici K, Rub U, de Vos RA, Jansen Steur EN, Braak E. Staging of brain pathology related to sporadic Parkinson's disease. Neurobiology of aging. 2003 MarApr;24(2):197-211.

5. Fortin DL, Nemani VM, Nakamura K, Edwards RH. The behavior of alpha-synuclein in neurons. Stanley F, Karen M, Lucien C, Stephen G R, editors. Movement Disorders. Wiley Subscription Services, Inc., A Wiley Company; 2010;25 Suppl 1(S1):S21-6.

6. Davidson WS, Jonas A, Clayton DF, George JM. Stabilization of alpha-synuclein secondary structure upon binding to synthetic membranes. The Journal of biological chemistry. 1998 Apr 17;273(16):9443-9.

7. Sidransky E, Samaddar T, Tayebi N. Mutations in GBA are associated with familial Parkinson disease susceptibility and age at onset. Neurology. 2009 Oct 27;73(17):1424-5authorreply1425-6.

8. Fanning S, Haque A, Imberdis T, Baru V, Barrasa MI, Nuber S, Termine D, Ramalingam N, Ho GPH, Noble T, Sandoe J, Lou Y, Landgraf D, Freyzon Y, Newby G, Soldner F, Terry-Kantor E, Kim T-E, Hofbauer HF, Becuwe M, Jaenisch R, Pincus D, Clish CB, Walther TC, Farese RV, Srinivasan S, Welte MA, Kohlwein SD, Dettmer U, Lindquist S, Selkoe D. Lipidomic Analysis of $\alpha$-Synuclein Neurotoxicity Identifies Stearoyl CoA Desaturase as a Target for Parkinson Treatment. Molecular cell. 2019 Mar 7;73(5):10018. PMCID: PMC6408259

9. Wang L, Das U, Scott DA, Tang Y, McLean PJ, Roy S. $\alpha$-synuclein multimers cluster synaptic vesicles and attenuate recycling. Curr. Biol. 2014 Oct 6;24(19):2319-26. PMCID: PMC4190006 
10. Cooper AA, Gitler AD, Cashikar A, Haynes CM, Hill KJ, Bhullar B, Liu K, Xu K, Strathearn KE, Liu F, Cao S, Caldwell KA, Caldwell GA, Marsischky G, Kolodner RD, Labaer J, Rochet J-C, Bonini NM, Lindquist S. Alpha-synuclein blocks ER-Golgi traffic and Rab1 rescues neuron loss in Parkinson's models. Science. 2006 Jul 21;313(5785):3248. PMCID: PMC1983366

11. Dettmer U, Ramalingam N, Saucken von VE, Kim T-E, Newman AJ, Terry-Kantor E, Nuber S, Ericsson M, Fanning S, Bartels T, Lindquist S, Levy OA, Selkoe D. Loss of native $\alpha$-synuclein multimerization by strategically mutating its amphipathic helix causes abnormal vesicle interactions in neuronal cells. Hum. Mol. Genet. 2017 Sep 15;26(18):3466-81. PMCID: PMC5884392

12. Galvagnion C, Buell AK, Meisl G, Michaels TCT, Vendruscolo M, Knowles TPJ, Dobson CM. Lipid vesicles trigger $\alpha$-synuclein aggregation by stimulating primary nucleation. Nat Chem Biol. 2015 Feb 2. PMCID: PMC5019199

13. Rovere M, Sanderson JB, Fonseca-Ornelas L, Patel DS, Bartels T. Refolding of helical soluble $\alpha$-synuclein through transient interaction with lipid interfaces. FEBS Lett. 2018 May;592(9):1464-72.

14. Kim S, Yun SP, Lee S, Umanah GE, Bandaru VVR, Yin X, Rhee P, Karuppagounder SS, Kwon S-H, Lee H, Mao X, Kim D, Pandey A, Lee G, Dawson VL, Dawson TM, Ko HS. GBA1 deficiency negatively affects physiological $\alpha$-synuclein tetramers and related multimers. PNAS. 2018 Jan 23;115(4):798-803. PMCID: PMC5789900

15. Nuber S, Rajsombath M, Minakaki G, Winkler J, Müller CP, Ericsson M, Caldarone B, Dettmer U, Selkoe DJ. Abrogating Native $\alpha$-Synuclein Tetramers in Mice Causes a LDOPA-Responsive Motor Syndrome Closely Resembling Parkinson's Disease. Neuron. 2018 Oct 10;100(1):75-5. PMCID: PMC6211795 